\title{
Stimulation of the pituitary-adrenal axis and of adrenocortical steroidogenesis ex vivo by administration of di-2-ethylhexyl phthalate to prepubertal male rats
}

\author{
Vichit Supornsilchai, Olle Söder and Konstantin Svechnikov \\ Pediatric Endocrinology Unit, Department of Woman and Child Health, Q 2:08, Karolinska Institutet and University Hospital, Astrid Lindgren Children's \\ Hospital, Solna, S-17176 Stockholm, Sweden \\ (Requests for offprints should be addressed to V Supornsilchai; Email: vichit.supornsilchai@ki.se)
}

\begin{abstract}
Phthalate esters exert deleterious effects on testicular physiology and, consequently, on reproduction and fertility. However, little is presently known concerning potential adverse effects of these environmental pollutants on the hormonal functions of the adrenal gland. Therefore, we have investigated the effects of administering to rats of different developmental ages di-2ethylhexyl phthalate (DEHP) on the hypothalamicpituitary-adrenal axis in vivo, as well as on adrenocortical steroidogenesis ex vivo. Oral exposure to DEHP once daily for 4 days elevated the serum levels of ACTH and corticosterone in rats 20 and 40 days of age, but not in adult, 60-day-old animals. Furthermore, primary cultures of adrenocortical cells isolated from 20- and 40-day-old rats treated with DEHP exhibited an enhanced capacity
\end{abstract}

to produce corticosterone in response to $\mathrm{ACTH}$, dibutyryl cAMP, and 22R-hydroxycholesterol, as well as increased ACTH-stimulated transport of endogenous cholesterol into mitochondria. Neither DEHP nor its major metabolite mono-2-ethylhexyl phthalate altered steroidogenesis in cultures of adrenocortical cells isolated from untreated rats. These findings demonstrate that in male rats, DEHP exerts an age-dependent influence on the pituitary-adrenocortical axis in vivo and adrenocortical steroidogenesis ex vivo. Such perturbation may be of pathological significance in connection with disorders of the hormonal stress response, especially in very young human beings.

Journal of Endocrinology (2007) 192, 33-39

\section{Introduction}

Di-2-ethylhexyl phthalate (DEHP), the phthalate present in the general environment at highest levels, is employed as a plasticizer in a wide variety of consumer products, including food packaging, cosmetics, household products, and medical devices (Parks et al. 2000). As a consequence, human exposure to DEHP, especially in medical settings, is significant and may be as high as $168 \mathrm{mg} /$ day (Kavlock et al. 2002). Such exposure is of particular concern in humans regarding fetuses and in extremely premature neonates under long-term care, in whom contact with DEHP-containing medical devices may raise safety questions on malformation of reproductive organs and neurological defects (Latini 2000).

In vivo, DEHP is rapidly metabolized by pancreatic lipase to mono-2-ethylhexyl phthalate (MEHP) and 2-ethylhexanol (Albro 1975, Albro et al. 1984). The MEHP thus formed is immediately further oxidized to a variety of more polar products in vivo (Albro 1975, 1983) as well as in in vitro systems (Albro et al. 1984). The wellcharacterized reproductive toxicity (Foster et al. 2001) and hepatocarcinogenecity exerted by DEHP in rodents have been suggested to actually be caused by MEHP (Sjöberg et al. 1986a,b).

Moreover, DEHP has anti-androgenic properties which include inhibition of fetal testosterone production and consequent malformations of male genitals (Akingbemi et al. 2001, Gray et al. 2001, Borch et al. 2004, 2006). At the same time, exposure of prepubertal rats to this compound for 4 weeks increases serum levels of luteinizing hormone (LH) and the capacity of Leydig cells to produce androgens (Akingbemi et al. 2001), suggesting that this phthalate may exert its antiandrogenic influence via the pituitary-gonadal axis. To date, most investigations of phthalate toxicology have focused on deleterious effects on the fertility and reproduction of humans and animals and little is known concerning the molecular effects on adrenocortical steroidogenesis, which plays a critical role in the regulation of stress responses and metabolic homeostasis. Therefore, the present study was designed to characterize the effects of exposing rats to DEHP on their pituitaryadrenal axis in vivo and adrenocortical steroidogenesis ex vivo. 


\section{Materials and Methods}

\section{Materials}

Dulbecco's modified Eagle's medium (DMEM) - Ham's nutrient mixture F-12, modified Eagle's medium (MEM), Hank's balanced salts solution (HBSS) without $\mathrm{Ca}^{2+}$ or $\mathrm{Mg}^{2+}$ and penicillin-streptomycin were all obtained from Gibco/BRL (Life Technologies). BSA (fraction V), Percoll, HEPES, collagenase type I, dibutyryl cyclic AMP $\left((\mathrm{Bu})_{2-}\right.$ cAMP), adrenocorticotropic hormone (ACTH), 22Rhydroxycholesterol (22R-OHC), DEHP, and aminoglutethimide (an inhibitor of cytochrome P450scc) were purchased from Sigma Chemical Co. MEHP was obtained from Tokyo Chemical Industry Co. Ltd Europe (Brussels, Belgium). Trilostane, an inhibitor of $3 \beta$-hydroxysteroid dehydrogenase, was provided by Stegram Pharmaceuticals (Billinghurst, Sussex, UK). Cell proliferation water soluble tetrazolium salt (WST-1) kit was purchased from Roche Diagnostic Gmbh.

\section{Animals}

Sprague-Dawley rats (B\&K Laboratories, Sollentuna, Sweden) at the initial age of 16,36 , and 56 days were divided into two groups so that there were no statistically significant differences between group body weight means. Each control and treatment group contained eight rats aged 16 days, 12 rats aged 36 days, and 15 rats aged 56 days. Animals with an initial age of 36 and 56 days were administered $750 \mathrm{mg} / \mathrm{kg}$ DEHP dissolved in corn oil or a corresponding volume of corn oil alone (controls) by gavage once daily for 4 days. The same protocol was used for younger rats with an initial age of 16 days, but the dose was reduced to $500 \mathrm{mg} / \mathrm{kg}$ DEHP as the higher dose showed acute toxicity. The described exposure to DEHP had no influence on the body weights of the animals irrespective of age group. The mean bodyweight in the control group was $320 \pm 11$ and $317 \pm 12 \mathrm{~g}$ in for DEHPtreated rats aged 60 days. For 40-day-old rats, the corresponding values were $160 \pm 5$ and $158 \pm 4 \mathrm{~g}$; for 20 -day-old rats, $50 \pm 2$ and $48 \pm 3 \mathrm{~g}$ respectively. Twentyfour hours after the last gavage, animals were anesthetized with pentobarbital and blood was collected by intracardiac puncture and samples were immediately placed into EDTAcoated tubes and centrifuged at $2500 \mathrm{~g}$ for $15 \mathrm{~min}$. The adrenals were removed for isolation of adrenocortical cells and plasma was collected and maintained at $-80{ }^{\circ} \mathrm{C}$ for later analysis of corticosterone and ACTH.

The experimental procedures were approved by the Northern Stockholm Committee for Ethical Animal Experimentation (registration no. N218/05).

\section{Isolation and culture of adrenocortical cells}

Adrenocortical cells were prepared from the adrenal glands of both control and DEHP-treated rats as described previously (Supornsilchai et al. 2005). Briefly, following removal of the fat and connective tissue, the glands were minced utilizing a scalpel and the pieces thus obtained incubated with type IV collagenase $(2 \mathrm{mg} / \mathrm{ml})$ for $20 \mathrm{~min}$ at $37^{\circ} \mathrm{C}$. The resulting cell suspension was then filtered through nylon gauze $(70 \mu \mathrm{m}$; Becton, Franklin Lakes, NJ, USA) and the cells collected by centrifugation at $300 \mathrm{~g}$ for $7 \mathrm{~min}$ and subsequently washed twice with MEM containing $0 \cdot 1 \%(\mathrm{w} / \mathrm{v})$ BSA. The washed cell pellet was resuspended in $2 \mathrm{ml}$ HBSS containing $0 \cdot 1 \%$ BSA, loaded on top of a discontinuous density gradient consisting of layers of 20,40,60, and 90\% Percoll dissolved in HBSS, and centrifuged at $800 \mathrm{~g}$ for $20 \mathrm{~min}$.

Following this density centrifugation, the adrenocortical cells recovered in the Percoll fractions with densities of 1.030 $1 \cdot 060 \mathrm{~g} / \mathrm{ml}$ were washed twice with HBSS containing $0 \cdot 1 \%$ BSA and resuspended in DMEM-F12 culture medium containing $0 \cdot 1 \%$ BSA together with $100 \mathrm{U}$ penicillin G sodium, $100 \mu \mathrm{g}$ streptomycin sulfate, and $25 \mu \mathrm{g}$ amphoterin B per milliliter. The viability of these cells, as assessed by Trypan blue exclusion, was routinely $>90 \%$.

Subsequently, 15000 adrenocortical cells were placed into each well of 96-well plates (Falcon, Franklin Lakes, NJ, USA). In the ex vivo experiments, the cells from control and DEHPtreated rats of different ages (20,40, and 60 days old) were cultured for $2 \mathrm{~h}$ at $37^{\circ} \mathrm{C}$ under an atmosphere containing $5 \%$ $\mathrm{CO}_{2}$, following which they were incubated in the absence or presence of ACTH $(0 \cdot 1,1$, or $10 \mathrm{ng} / \mathrm{ml}),(\mathrm{Bu})_{2} \mathrm{CAMP}$ $(1 \mathrm{mM})$, and/or $22 \mathrm{R}-\mathrm{OHC}(10 \mu \mathrm{M})$ for $24 \mathrm{~h}$. $22 \mathrm{R}-\mathrm{OHC}$ is a membrane-permeable form of cholesterol which is widely used as a tool to bypass the active cholesterol transport processes and to test the activity of downstream steroidogenic enzymes. No alterations in cell viability or morphology were observed after this treatment as assessed by light microscopy and the WST-1 test. The reagent WST-1 is an uncolored tetrazolium salt that is cleaved to colored formazan by cellular enzymes. The amount of formazan dye-formed correlates directly with the number of metabolically active cells in the culture.

In the case of in vitro experiments, adrenocortical cells isolated from 20-, 40-, or 60-day-old rats were cultured together with $10 \mu \mathrm{M}$ DEHP or MEHP for $24 \mathrm{~h}$ at $37^{\circ} \mathrm{C}$ under $5 \% \mathrm{CO}_{2}$, after which fresh medium containing DEHP or MEHP at the same concentration with or without ACTH $(1 \mathrm{ng} / \mathrm{ml})$ or $(\mathrm{Bu})_{2} \mathrm{cAMP}(1 \mathrm{mM})$ was added and incubation continued for an additional $6 \mathrm{~h}$. Again no alterations in cell viability or morphology were associated with such exposure to DEHP or MEHP. The concentration $10 \mu \mathrm{M}$ DEHP or MEHP was chosen since pilot experiments showed lack of effect at $1 \mu \mathrm{M}$, and no different effect at $100 \mu \mathrm{M}$ of these compounds. All cultures were performed under serum-free conditions.

\section{Determination of hormone concentrations}

Samples of plasma and medium from the adrenocortical cell cultures were stored at $-20{ }^{\circ} \mathrm{C}$ prior to determination of the concentration of corticosterone present employing the 
Coat-a-Count RIA kit (Diagnostic Products Corp., Los Angeles, CA, USA) in accordance with the manufacturer's instructions, as well as the concentration of pregnenolone by RIA employing specific antiserum (Fitzgerald Industries, Concord, MA, USA) and $\left(7-{ }^{3} \mathrm{H}(\mathrm{N})\right.$, pregnenolone (14 Ci/mmol; New England Nuclear Life Science Products, Boston, MA, USA). For assay of plasma levels of ACTH, blood samples from control and DEHP-treated rats were collected in tubes containing EDTA and plasma prepared by centrifugation and stored at $-80^{\circ} \mathrm{C}$ prior to quantitation of ACTH employing an immunoassay (Mdbiosciences, Zürich, Switzerland) in accordance with the manufacturer's instructions.

\section{Monitoring cholesterol transport}

For this purpose, triplicate samples each containing 30000 adrenocortical cells isolated from control or DEHP-treated rats 20,40, or 60 days of age were placed into each well of 96-well Falcon plates (Falcon), where they were first incubated at $37^{\circ} \mathrm{C}$ under an atmosphere containing 5\% $\mathrm{CO}_{2}$ for $2 \mathrm{~h}$. Thereafter, fresh medium containing aminoglutethimide (AMG) $(0.5 \mathrm{mM})$, an inhibitor of cytochrome P450scc, and trilostane $(5 \mu \mathrm{M})$, an inhibitor of $3 \beta$-hydroxysteroid dehydrogenase, was added and incubation continued for an additional $30 \mathrm{~min}$, following which ACTH $(0 \cdot 1 \mathrm{ng} / \mathrm{ml})$ was added and incubation performed for an additional $2 \mathrm{~h}$. Inhibition of cholesterol metabolism in mitochondria by AMG and trilostane results in accumulation of this steroid in these organelles upon hormonal stimulation (Potts et al. 1978, Robert et al. 2005).

Subsequently, the cells were washed twice with medium and then incubated with trilostane $(5 \mu \mathrm{M})$ in AMG-free medium at $37^{\circ} \mathrm{C}$ under $5 \% \mathrm{CO}_{2}$ for $1 \mathrm{~h}$. Under these conditions, the amount of pregnenolone produced by the cells reflects the amount of cholesterol available to the cytochrome P450scc system (Potts et al. 1978). The pregnenolone concentrations in the culture media were determined as described previously.

\section{Assay of hormone-sensitive lipase}

Whole adrenal glands from DEHP-treated or control rats were placed in cold $50 \mathrm{mM}$ Tris-Cl buffer $(\mathrm{pH} 7 \cdot 0$ ) containing $250 \mathrm{mM}$ sucrose, $1 \mathrm{mM}$ EDTA, and a cocktail of protease inhibitors (Roche) and sonicated twice for $10 \mathrm{~s}$ each time at $25^{\circ} \mathrm{C}$. Debris was subsequently removed from these sonicates by centrifugation at $14000 \mathrm{~g}$ for $10 \mathrm{~min}$ at $4{ }^{\circ} \mathrm{C}$, after which the supernatant was collected and its protein concentration determined by the Bradford (1976) procedure. The substrate for this assay was prepared by adding $0.04 \mu \mathrm{mol}$ cholesteryl- $\left[{ }^{14} \mathrm{C}\right]$ oleate (Amersham) and a mixture of phosphatidylcholine and phosphatidylinositol $(3: 1,175 \mu \mathrm{g} /$ tube) to $2 \mathrm{ml}$ of $100 \mathrm{mM}$ potassium phosphate buffer ( $\mathrm{pH} 7 \cdot 0)$ and sonicating for $2 \mathrm{~min}$ immediately prior to use.

The enzyme activity was measured by incubating $150 \mu \mathrm{l}$ of this substrate with $50 \mu \mathrm{l}$ of the adrenal extract at $37^{\circ} \mathrm{C}$ for
$30 \mathrm{~min}$. The reaction was stopped by addition of $1.6 \mathrm{ml}$ methanol:chloroform:heptane (10:9:2), after which $0.5 \mathrm{ml}$ borate-carbonate buffer $(0 \cdot 1 \mathrm{M}, \mathrm{pH} 10 \cdot 5)$ was added, the tubes mixed by vortexing and centrifuged for $20 \mathrm{~min}$, and finally, $0.5 \mathrm{ml}$ aliquots of the upper phase thus obtained counted in a Beckman scintillation counter. The activities are expressed as pmol cholesteryl oleate hydrolyzed/ $\mu \mathrm{g}$ protein per $\mathrm{h}$.

\section{Statistical analysis}

The differences between various values were examined for statistical significance by one-way ANOVA, followed by the Student-Newman-Keul's or Dunn's test, employing the SigmaStat (v 3.00) package (SPSS, Inc., Chicago, IL, USA). To test the hypothesis that age and treatment significantly affected ACTH and corticosterone values, two-way ANOVA was used. A $P$ value of $<0 \cdot 05$ was considered to be statistically significant. The levels of corticosterone and pregnenolone in culture media were expressed and analyzed as a percentage of the corresponding control value, in order to compensate for a variation of these control levels between experiments.

\section{Results}

Age-dependent elevations in the levels of ACTH and corticosterone in male rat plasma in response to exposure to DEHP

Administration of DEHP to 20- and 40-day-old rats for 4 days by oral gavage resulted in 3 - and $2 \cdot 2$-fold respectively, increases in their plasma concentrations of ACTH (Fig. 1A). Furthermore, such exposure to this phthalate enhanced the level of corticosterone in the plasma of these rats by 100 and $40 \%$ respectively (Fig. 1B). In contrast, identical treatment of rats aged 60 with DEHP did not significantly influence these same parameters (Fig. 1A and B). Analysis of the data by two-way ANOVA showed significant age-dependent differences in ACTH and corticosterone levels in the studied rats $(P<0 \cdot 001$, $F=12.6$ and 13.97 respectively) and confirmed a marked effect of DEHP on the levels of the investigated hormones $(P<0 \cdot 01, P<0 \cdot 001, F=7 \cdot 6$ and $21 \cdot 3$ respectively $)$.

Age-dependent enhancement of ACTH-stimulated steroidogenesis by cultures of adrenocortical cells ex vivo isolated from DEHP-treated male rats

As illustrated in Fig. 2, the production of corticosterone by cultures of adrenocortical cells isolated from 20- and 40-dayold rats administered DEHP was stimulated more potently by ACTH than the corresponding production by cells isolated from control animals. In contrast, no such difference was observed in the case of 60-day-old rats (Fig. 2C). 


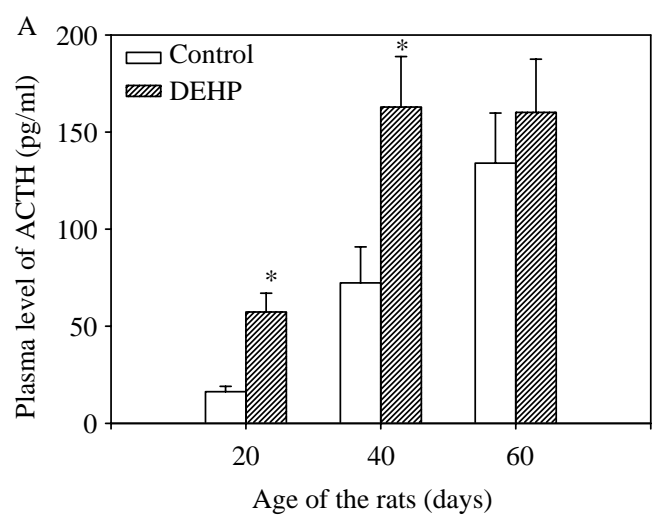

$\mathrm{B}$

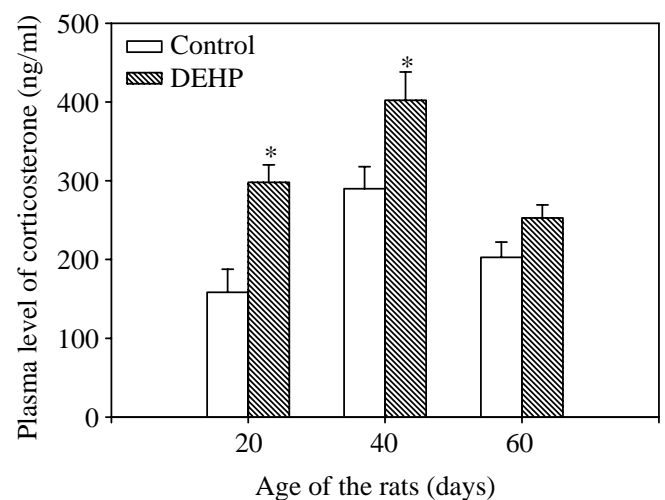

Figure 1 Plasma levels of (A) ACTH and (B) corticosterone in male rats of different ages exposed to DEHP (500 mg/kg at 20 days of age and $750 \mathrm{mg} / \mathrm{kg}$ at the ages of 40 and 60 days). DEHP was administered in corn oil by oral gavage for 4 days, while control animals received corn oil alone. Each bar (treated group and controls) represents the mean \pm S.E.M. $(n=8,20$ days; $n=12$, 40 days; $n=15,60$ days). ${ }^{*} P<0.05$ compared with the corresponding control values.

Age-dependent stimulation of steroidogenesis by adrenocortical cells isolated from DEHP-treated male rats cultured in the presence of $(B u)_{2} c A M P$ or $22 R-O H C$ ex vivo

When steroidogenesis was stimulated downstream from the ACTH receptor by incubation in the presence of the second messenger $(\mathrm{Bu})_{2} \mathrm{cAMP}$, corticosterone production by cultures of adrenocortical cells isolated from DEHPtreated rats aged 20 and 40 days, but not 60 days was also significantly enhanced (2.3- and 2-fold respectively) compared with the corresponding control values (Fig. 3A). Furthermore, 22R-OHC, a derivative of cholesterol that diffuses freely across biological membranes, was more rapidly metabolized to corticosterone by cells isolated from DEHP-treated 20- and 40-day-old rats, with, once again, no effect being observed in cells from rats aged 60 days (Fig. 3B). Together, these findings indicate that in young, prepubertal rats, DEHP stimulates the adrenocortical enzymes involved in steroidogenesis.

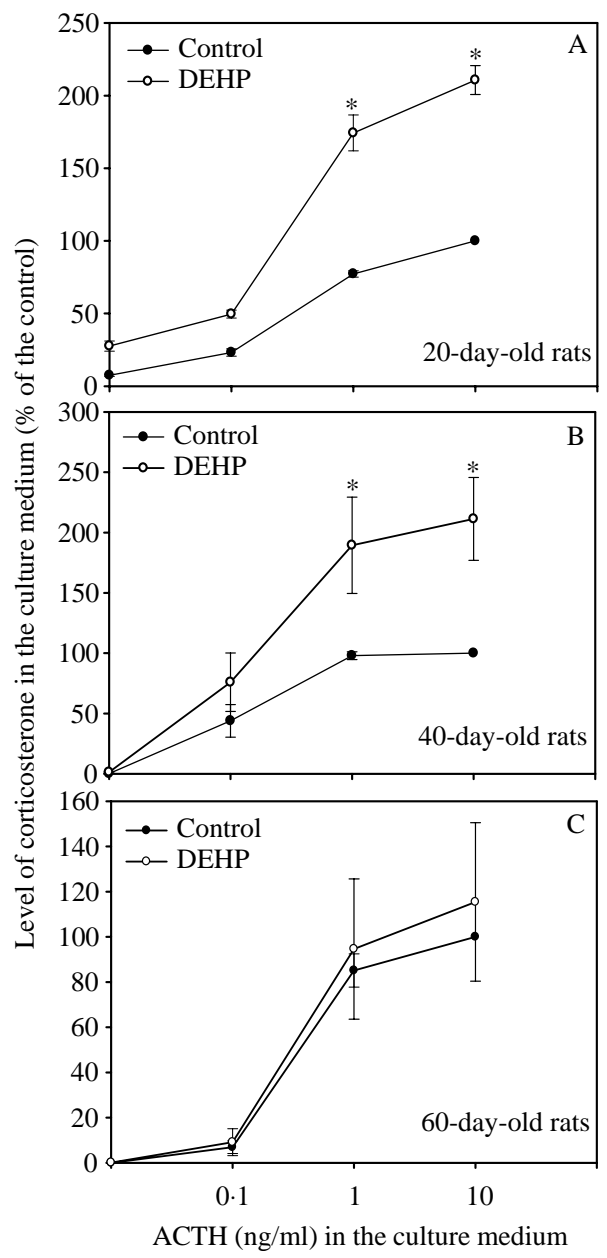

Figure 2 Effects of ACTH on corticosterone production by cultures of adrenocortical cells isolated from DEHP-treated and control male rats aged (A) 20, (B) 40, and (C) 60 days. Following incubation of these cells with varying concentrations of ACTH for $6 \mathrm{~h}$, the concentrations of corticosterone in the culture media were determined by RIA. The results presented are the means \pm S.E.M. of three independent preparations of adrenocortical cells. ${ }^{*} P<0 \cdot 05$ compared with the corresponding control values.

Age-dependent stimulation of cholesterol transport in cultures of adrenocortical cells isolated from DEHP-treated male rats

Since the transport of cholesterol into mitochondria is essential for the maintenance of a high rate of steroidogenesis in adrenocortical cells (Jefcoate 2002), we examined whether the stimulatory effect of DEHP on steroid production was associated with the activation of this transport process. Indeed, the levels of pregnenolone produced which reflect the availability of cholesterol to the cytochrome P450scc system (Hanukoglu 1992) by the cultures of adrenocortical cells isolated from DEHP-treated rats 20 and 40 days of age were enhanced significantly by 40 and $50 \%$ respectively; $(P<0 \cdot 05)$, whereas exposure of 60-day-old rats to DEHP did not alter cholesterol transport in the isolated cells (Fig. 4). 

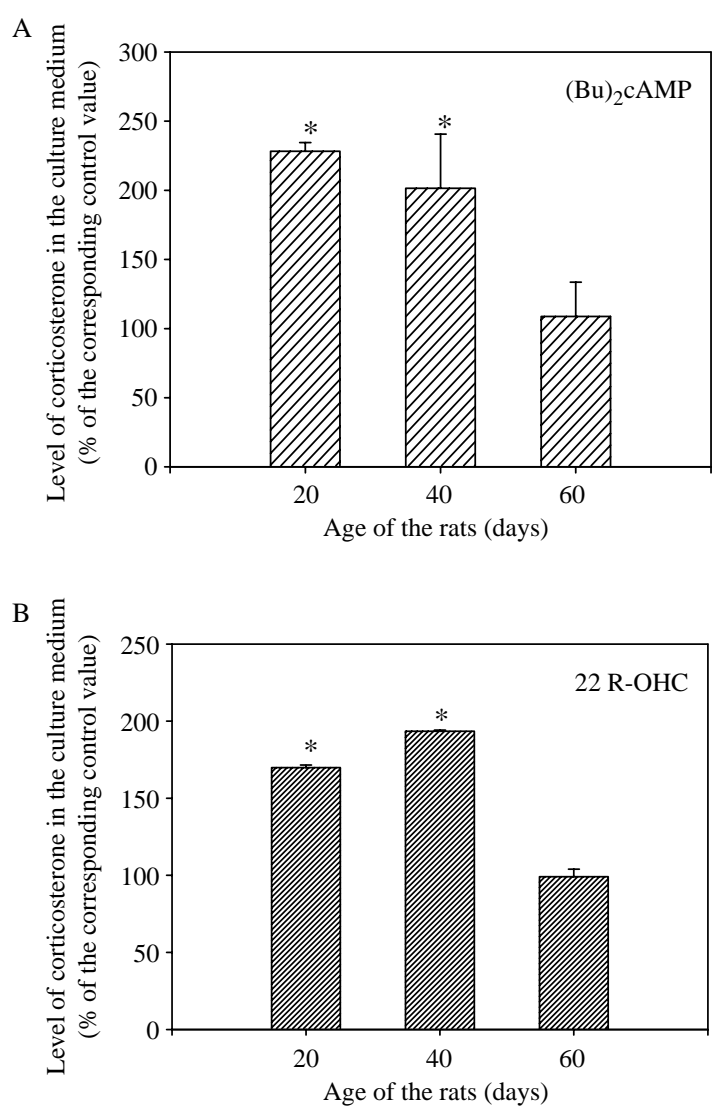

Figure 3 Effects of $(\mathrm{Bu})_{2} \mathrm{CAMP}$ or $22 \mathrm{R}-\mathrm{OHC}$ on corticosterone production by cultures of adrenocortical cells isolated from DEHPtreated and control male rats aged 20, 40, and 60 days. Following incubation of these cells with $1 \mathrm{mM}(\mathrm{Bu})_{2} \mathrm{CAMP}$ or $10 \mu \mathrm{M} 22 \mathrm{R}-\mathrm{OHC}$ for $6 \mathrm{~h}$, the concentrations of corticosterone in the culture media were determined by RIA. The mean basal (control) values were $127 \pm$ $3 \mathrm{ng} / \mathrm{ml}$ (20 days), $202 \pm 55 \mathrm{ng} / \mathrm{ml}$ (40 days), $198 \pm 48 \mathrm{ng} / \mathrm{ml}$ ( 60 days) for $(\mathrm{Bu})_{2} \mathrm{CAMP}$ treatment, and $231 \pm 6 \mathrm{ng} / \mathrm{ml}$ (20 days), $463 \pm$ $140 \mathrm{ng} / \mathrm{ml}$ (40 days), and $500 \pm 46 \mathrm{ng} / \mathrm{ml}$ (60 days) for $22 \mathrm{R}-\mathrm{OHC}-$ induced corticosterone production. The results presented are the means \pm S.E.M. of three independent preparations of adrenocortical cells. ${ }^{*} P<0 \cdot 05$ compared with the corresponding control values.

Lack of influence of DEHP on hormone-sensitive lipase activity in the adrenal glands of male rats

Hormone-sensitive lipase (HSL) is involved in regulating intracellular cholesterol metabolism. The activity of HSL remained unaltered in the adrenal glands of the rats of all three age groups upon exposure to DEHP versus control (mean \pm S.E.M., pmol/ $\mu \mathrm{g}$ protein per h); 20 days, $1 \cdot 0 \pm 0 \cdot 1$ vs $0 \cdot 9 \pm 0 \cdot 2$; 40 days, $1 \cdot 1 \pm 0 \cdot 1$ vs $0 \cdot 8 \pm 0 \cdot 1$; and 60 days, $0 \cdot 9 \pm 0 \cdot 1$ vs $0 \cdot 9 \pm 0 \cdot 1$.

Lack of a direct effect of DEHP or MEHP on the stimulation of in vitro steroidogenesis in male rat adrenocortical cells by ACTH or $(B u)_{2} C A M P$

The effects of DEHP and MEHP, its major metabolite, in vitro were studied to compare if these chemicals are acting in the same

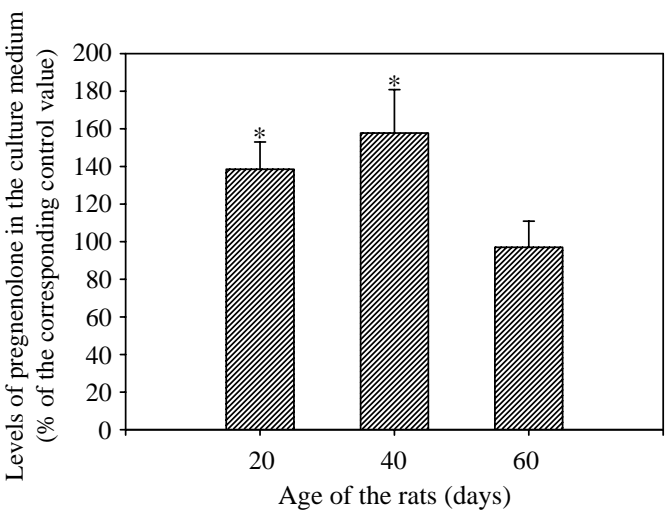

Figure $4 \mathrm{ACTH}$-stimulated transport of cholesterol in cultures of adrenocortical cells isolated from DEHP-treated and control male rats of different ages. Following pretreatment of these cells with aminoglutethimide (AMG; $0.5 \mathrm{mM}$ ) and trilostane $(5 \mu \mathrm{M})$ for $30 \mathrm{~min}$ and subsequent incubation in the presence of $0 \cdot 1 \mathrm{ng}$ ACTH per milliliter for $2 \mathrm{~h}$, the pregnenolone levels in the culture media were determined by $\mathrm{RIA}$. The mean basal (control) values of $\mathrm{ACTH}$-induced pregnenolone production by cultured adrenocortical cells from 20-, 40-, and 60-dayold rats were $10 \pm 0 \cdot 4,68 \pm 10$, and $75 \pm 14 \mathrm{ng} / \mathrm{ml}$ respectively. Each experiment was performed independently thrice with similar results. ${ }^{*} P<0.05$ compared with the corresponding control values.

way as in in vivo experiments. Neither DEHP nor MEHP, both tested at a concentration of $10 \mu \mathrm{M}$, had any statistically significant effect on in vitro activation of steroidogenesis in rat adrenocortical cells by ACTH or $(\mathrm{Bu})_{2}$ cAMP in any of the three age groups studied (data not shown).

\section{Discussion}

Our present findings demonstrate that short-term treatment of young (20- and 40-day-old) rats with DEHP stimulated both the pituitary-adrenal axis in vivo and adrenocortical steroidogenesis ex vivo. In contrast, no such effects were observed in adult, sexually mature animals, suggesting that the susceptibility of these processes to DEHP is dependent on the stage of development. We also found that the responsiveness of adrenocortical cells to ACTH in vivo is an age-dependent process. Despite the fact that basal ACTH levels were much higher in adult rats compared with young ones, plasma corticosterone values were lower suggesting a lower adrenal sensitivity to ACTH in the adult group. Based on our data, we calculated that the adrenals from 20 - and 40-day-old rats secreted 6.5- and $2 \cdot 7$-fold higher levels of corticosterone in response to $1 \mathrm{pg}$ ACTH than adult 60-day-old rats. These results are in line with the observation showing that aged rats have enhanced levels of ACTH, resulting in hypertrophy of the zona fasciculata and reticularis (Rebuffa et al. 1992). In addition, although DEHP exposure did not affect ACTH levels of adult rats, the absolute values in the DEHP-treated adult rats were comparable with those observed in 40-day-old rats.

The doses of DEHP used in this study were relatively high compared with those observed in human subjects with long-term exposure to DEHP-containing devices. 
However, the premature neonates were found to be exposed to DEHP levels up to 100 times above the limit values. Depending on the intensity of the medical care, the exposure can reach up to $1780 \mu \mathrm{g} / \mathrm{kg}$ per day in such infants (Koch et al. 2006). Further, to correlate toxic effects observed in animals with acceptable levels of exposure for humans, tenfold increases in DEHP exposure are commonly used for analysis of inter- and intraspecies variability ( $\mathrm{Xu}$ et al. 2005).

We suggest that the exposure of prepubertal, developing male rats to DEHP stimulates the pituitary gland to produce ACTH, which in turn activates adrenocortical steroidogenesis. Accordingly, adrenocortical cells isolated from such rats exhibit an enhanced capacity to produce corticosterone in response to $\mathrm{ACTH},(\mathrm{Bu})_{2} \mathrm{cAMP}$, or $22 \mathrm{R}-\mathrm{OHC}$, as well as elevated transport of cholesterol into their mitochondria. All these cellular processes appear to be consequences of activation of a cAMP-protein kinase A (PKA) signaling pathway by ACTH. In contrast, no activation of hormonesensitive lipase, which regulates the size of the pool of free cholesterol available for steroidogenesis, was detected in DEHP-treated animals of any age.

In an attempt to determine whether DEHP or its major metabolite, MEHP can directly stimulate steroidogenesis by adrenocortical cells, cultures of such cells isolated from untreated rats were incubated with these compounds. The lack of any significant effect on either ACTH- or $(\mathrm{Bu})_{2}$ cAMP-induced steroidogenesis, indicates that DEHP and/or its metabolite(s) act directly on the pituitary-adrenal axis. This suggestion is in line with the findings that chronic administration of DEHP to male Fisher 344 rats results in hypertrophy of gonadotropes in the anterior pituitary and causes pituitary tumors (Kluwe et al. 1982). This proposal is also in agreement with the observation that exposure of prepubertal male rats to DEHP for 28 days stimulates their pituitary-gonadal axis and enhances the capacity of their Leydig cells to synthesize androgens (Akingbemi et al. 2001).

The mechanisms underlying our observations are not presently clear. One possibility is that DEHP inhibits the negative feedback effect of corticosterone on the hypothalamus and/or the pituitary of developing male rats, thereby resulting in hypercorticotropism.

Although there is no available information on the interaction of DEHP or its metabolites with the glucocorticoid receptor (GR), an indirect effect of phthalates on GR via modulation of peroxisome proliferator-activated receptor activities cannot be excluded. This type of nuclear receptors belongs to ligand-dependent transcription factors that are part of phthalate-signaling machinery regulating transcription of several target genes (Berger \& Moller 2002).

The hormonal response of the adrenal glands of young rats to treatment with DEHP is similar to that characteristic of stress, suggesting that DEHP could be considered as a chemical stressor acting on the pituitary-adrenal axis. Exposure to stressors is known to activate the hypothalamic-pituitary-adrenal (HPA) axis (Dunn \& Berridge 1990) by stimulating a cascade of events involving the release of corticotropin-releasing factor (CRF) from the paraventricular nucleus (PVN) of the hypothalamus that leads to enhanced secretion of ACTH from the pituitary. This hormone stimulates corticosterone secretion from the adrenal cortex into the circulatory system. One possible mechanism by which DEHP could activate the HPA axis in young animals is activation of cytokine expression in the hypothalamus. This hypothesis is supported by several observations. First, acute exposure (hours) to phthalates was found to induce a rapid and transient increased production of interleukin (IL)-1 by the rat testis (Granholm et al. 1992), and mono phthalates were recently shown to enhance IL-6 and IL-8 syntheses in the human epithelial A 549 cell line (Jepsen et al. 2004). Secondly, proinflammatory cytokines have been reported to induce release of CRF from the PVN and augment neurochemical stimulation of the pituitary gland (Turnbull et al. 1998). Apart from a stress response triggered by immuneinflammatory stimuli, cytokines may be involved in mediating hypothalamic responses to different types of stress. Various forms of psychological stress increased hypothalamic IL-1 $\beta$ levels and enhanced circulating level of IL-1 $\beta$ inducing release of the CRF and activation of the HPA axis (Nguyen et al. 2000). Further, DEHP-induced stimulation of the HPA axis in young rats could also be mediated by modulation of the neurotransmitter system in other structures of the brain located upstream the hypothalamus. Such regulation has been shown for cocaine, inducing ACTH and corticosterone secretion via a dopaminemediated mechanism (Borowsky \& Kuhn 1991), which include activation of mesocorticolimbic dopamine transmission and CRF secretion from PVN (Sorg 1992).

It can be speculated that the age dependency of the susceptibility to DEHP may reflect differences in the metabolism of this phthalate by immature and adult rats. DEHP is extensively metabolized after all routes of uptake. In a first and fast step, DEHP is cleaved into the monoester MEHP, which is again fast and extensively further metabolized by different oxidation reactions (Schmid \& Schlatter 1985). Therefore, differences in the levels and/or nature of hepatic metabolites of DEHP might explain, at least in part, the higher susceptibility of the hypothalamus and/or pituitary gland of younger male rats. A cocktail of DEHP-derived metabolites could directly stimulate the hypothalamus and/or pituitary of developing rats, thereby resulting in hypercorticotro pism. This suggestion is in line with the observation that the ability to excrete DEHP metabolites, e.g. MEHP, mono (2-ethyl-5hydroxyhexyl)phthalate (MEHHP), mono(2-ethy1-5-oxo-hexyl)phthalate (MEOHP) in urine is age dependent (Koch et al. 2004). However, at the present stage, we lack knowledge on which one, if any, of these metabolites that are involved in the activation of the HPA axis in young rats.

In summary, our present investigation is the first to demonstrate that exposure of male rats to DEHP leads to an age-dependent activation of the pituitary-adrenocortical axis in vivo and of adrenocortical steroidogenesis ex vivo. These novel observations may indicate a specific susceptibility of the pituitary-adrenocortical axis of immature animals to this phthalate. From a translational perspective, the present findings 
may have implications for human beings and in particular for newborns and small children, including premature infants, who may also be more exposed to environmental levels of phthalates than adults.

\section{Acknowledgements}

The authors are grateful to Ann-Christine Eklöf and Josephine Forsberg for their help with administration of DEHP to rats by gavage. This work was supported financially by the EU Commission (CASCADE No. E FOOD-CT2004-506319; PIONEER STREP FOOD-CT-2005513991), the Swedish Research Council (No. 2002-5892), the Swedish Environmental Protection Agency (ReproSafe), the Swedish Children's Cancer Fund, the Frimurare Barnhuset Foundation in Stockholm, Sällskapet Barnavård, Stiftelsen Samariten, and Karolinska Institute. The authors declare that there is no conflict of interest that would prejudice the impartiality of this scientific work.

\section{References}

Akingbemi BT, Youker RT, Sottas CM, Ge R, Katz E, Klinefelter GR, Zirkin BR \& Harday MP 2001 Modulation of rat Leydig cell steroidogenic function by di(2-ethylhexyl) phthalates. Biology of reproduction 65 1252-1259.

Albro PW 1975 The metabolism of 2-ethylhexanol in rats. Xenobiotica 10 625-636.

Albro PW, Tondeur I, Marbury D, Jordan S, Schroeder J \& Corbett JT 1983 Polar metabolites of di-(2-ethylhexyl)phthalate in the rat. Biochimica Biophysica Acta 760 283-292.

Albro PW, Chae K, Philpot R, Corbette JT, Schroeder J \& Jordan S 1984 In vitro metabolism of mono-2-ethylhexyl phthalate by microsomal enzymes. Similality to omega-and (omega-1) oxidation of fatty acids. Drug Metabolism and Disposition 12 742-748.

Berger J \& Moller DE 2002 The mechanisms of action of PPARs. Annual Review of Medicine $\mathbf{5 3}$ 409-435.

Borch J, Ladefoged O, Hass U \& Vinggaard AM 2004 Steroidogenesis in fetal male rats is reduced by DEHP and DINP, but endocrine effects of DEHP are not modulated by DEHA in fetal, prepubertal and adult male rats. Reproductive Toxicology 18 53-61.

Borch J, Metzdorff SB, Vinggaard AM, Brokken L \& Dalgaad M 2006 Mechanisms underlying the anti-androgenic effects of diethylhexyl phthalate in fetal rat testis. Toxicology 223 144-155.

Borowsky B \& Kuhn CM 1991 Chronic cocaine administration sensitizes behavioral but not neuroendocrine responses. Brain Research 15 301-306.

Bradford MM 1976 A rapid and sensitive method for the quantitation of microgram quantities of protein utilizing the principle of protein-dye binding. Analytical Biochemistry 72 248-254.

Dunn AJ \& Berridge CW 1990 Physiological and behavioral response to corticotrophin-releasing factor administration: is CRF a mediator of anxiety or stress response? Brain Research Reviews 15 71-100.

Foster PM, Mylchreest E, Gaido KW \& Sar M 2001 Effects of phthalate esters on the developing reproductive tract of male rats. Human Reproduction Update 7 231-235.

Granholm T, Creasy DM, Pollanen P \& Soder O 1992 Di-n-pentyl phthalateinduced inflammatory changes in the rat testis are accompanied by local production of a novel lymphocyte activating factor. Journal of Reproductive Immunology 21 1-14.

Gray LE, Ostby J, Furr J, Wolf CJ, Lambright C, Parks L, Veeramachaneni DN, Wilson V, Price M, Hotchkiss A et al. 2001 Effects of environmental antiandrogens on reproductive development in experimental animals. Human Reproduction Update 7 248-264.
Hanukoglu A 1992 Steroidogemic enzymes: structure, function and role in regulation of steroid hormone biosynthesis. Journal of Steroid Biochemistry and Molecular Biology 43 779-804.

Jefcoate C 2002 High-flux mitochondrial cholesterol trafficking, a specialized function of the adrenal cortex. Journal of Clinical Investigation 110 881-890.

Jepsen KF, Abildtrup A \& Larsen ST 2004 Monophthalates promote IL-6 and IL-8 production in the human epithelial cell line A549. Toxicology In Vitro 18 265-269.

Kavlock R, Boekelheide K, Chapin P, Cunningham M, Faustman E, Foster P, Golub M, Henderson R, Hinberg I, Little R et al. 2002 NTP center for the evaluation of risks to human reproduction: Phthalates Expert Panel report on the reproduction and developmental toxicity of di(2-ethylhexyl) phthalate. Reproductive Toxicology 16 629-655.

Kluwe WM, Haseman JK, Douglas JF \& Huff JE 1982 The carcinogenicity of dietary di(2-ethylhexyl) phthalate (DEHP) in Fischer 344 rats and B6C3F1 mice. Journal of Toxicology and Environmental Health 10 797-815.

Koch HM, Drexler H \& Angerer J 2004 Internal exposure of nursery-school children and their parents and teachers to di(2-ethylhexyl) phthalate (DEHP). International Journal of Hygiene and Environmental Health 207 15-22.

Koch HM, Preuss R \& Angerer J 2006 Di (2-ethylhexyl)phthalate (DEHP): human metabolism and internal exposure an update and latest results. International Journal of Andrology 29 155-165.

Latini G 2000 Potential hazards of exposure to di-(2-ethylhexyl) phthalate in babies: a review. Biology of the Neonate 78 268-276.

Nguyen KT, Deak T, Will MJ, Hansen MK, Hunsaker BN, Fleshner M, Watkins LR \& Maier SF 2000 Timecourse and corticosterone sensitivity of the brain, pituitary, and serum interleukin-1 beta protein response to acute stress. Brain Research 859 193-201.

Parks LG, Ostby JS, Lambright CR, Abbott BD, Klinefelter GR, Barlow NJ \& Gray LE 2000 The plasticizer diethylhexyl phthalate induces malformations by decreasing fetal testosterone synthesis during sexual differentiation in the male rat. Toxicological Sciences $\mathbf{5 8}$ 339-349.

Potts GO, Creange JE, Hardomg HR \& Schane HP 1978 Trilostane, an orally active inhibitor of steroid biosynthesis. Steroids 32 257-267.

Rebuffa P, Belloni AS, Rocco S, Andreis PG, Neri G, Malendo-Wicz LK, Gottardo G, Mazzocchi G \& Nussdorfer GG 1992 The effects of ageing on the morphology and function of the zonae fasciculate/reticularis of the rat adrenal cortex. Cell and Tissue Research 270 265-272.

Robert WB, John CH \& Edgar SDC 2005 Aromatase inhibitors in the treatment of breast cancer. Endocrine Reviews 26 331-345.

Schmid P \& Schlatter C 1985 Excretion and metabolism of di(2-ethylhexyl) phthalate in man. Xenobiotica 15 251-256.

Sjöberg P, Bondesson U, Gray TJ \& Plöen L 1986a Effects of di-(2-ethylhexyl) phthalate and five of its metabolites on rat testis in vivo and in in vitro. Acta Pharmacologica et Toxicologica 58 225-233.

Sjöberg P, Lindquist NG \& Plöen L 1986b Age-dependent response of the rat testes to di-(2-ethylhexyl) phthalate. Environmental Health Perspectives 65 237-242.

Sorg BA 1992 Mesocorticolimbic dopamine systems: cross-sensitization between stress and cocaine. Annals of the New York Academy of Sciences 28 $136-144$.

Supornsilchai V, Svechnikov K, Seidlova-Wuttke W \& Soder O 2005 Phytoestrogen resveratrol suppresses steroidogenesis by rat adrenocortical cells by inhibiting cytochrome P450c21-hydroxylase. Hormone Research 64 280-286.

Turnbull AV, Kim CK, Lee S \& River CL 1998 Influence of carbon monoxide, and its interaction with nitric oxide, on the adrenocorticotropin hormone response of the normal rat to a physico-emotional stress. Journal of Neuroendocrinology 10 793-802.

Xu Y, Cook TJ \& Knipp GT 2005 Effects of di-(2-ethylhexyl)-phthalate (DEHP) and its metabolites on fatty acid homeostasis regulating protein in rat placental HRP-1 trophoblast cells. Toxicological Sciences 84 287-300.

Received 2 August 2006

Received in final form 3 October 2006

Accepted 5 October 2006

Made available online as an Accepted Preprint 12 October 2006 